\title{
Hydration kinetics of calcium sulphate hemihydrate modified by water-soluble polymers Patrycja Mróz ${ }^{1 *}$, Maria Mucha ${ }^{2}$
}

Faculty of Process and Environmental Engineering, Lodz University of Technology, Wólczańska 215, 90-924 Łódź, Poland

Abstract - Pastes based on gypsum (calcium sulphate hemihydrate) and two chosen water-soluble polymer admixtures, i.e. hydroxyethylmethyl cellulose (HEMC) and poly(vinyl acetate) (PVAC) were prepared. The impacts of the polymers on gypsum setting, as well as thermal and mechanical properties were studied. Heat effect and the rate of setting depending on water to gypsum ratio and the presence of admixtures were measured. The results have shown a strong effect of the polymer admixture (1\%) on the prolongation of gypsum setting time. The presence of polymer molecules in water solution hinders the crystallization process of gypsum dihydrate. HEMC and PVAC have also a significant influence on gypsum mechanical properties especially at low water content. Kinetics of the setting process of gypsum hemihydrate is discussed.

Keywords - admixture, gypsum, heat of hydration/crystallization, hydroxyethylmethyl cellulose, poly(vinyl acetate), setting.

\section{INTRODUCTION}

Dramatically altering setting rates as well as microstructures and properties of cement or gypsum products are often accompanied by the use of admixtures. They include accelerators or retarders of setting. Better understanding of the chemistry and physics of product hydration and setting is important. More progress can be made by systematically examining how the setting rate is influenced by chemical admixtures.

Also gypsum industry turns to sustainable development and production of greener concrete [1-6]. Thus, instead of toxic materials (e.g. $\mathrm{KNO}_{3}, \mathrm{NH}_{4} \mathrm{Cl}$, resins such as sulfonated melanin or sulfonated naphthalene [7]) water-soluble (environment friendly) polymers are used.

Gypsum products are known for their fire resistance, thermal insulation and acoustic properties. However, due to low water resistance and mechanical strength, gypsum is not a suitable material for external construction works. The protection of gypsum requires prevention against penetration of moisture to avoid any damage [8]. Polymer plasticizers are often used as additives in construction materials (gypsum, concrete) in order to reduce water content which generally leads to higher strength of the product, extended or reduced setting time and lowering the possibility of mixture separation. A longer duration of the mixture adequate consistency improves workability and flowability of gypsum and concrete.

Appropriate mixing of hemihydrate sulphate (gypsum) with $1 \%$ of polymer (e.g. cellulose derivatives) substantially modifies the mechanical properties, rate of setting (crystallization) and water retention of the material obtained. This has an important impact on the application.

Hemihydrate sulphate (gypsum) hydration involves a set of coupled chemical and physical processes $[9,10]$ :

1. Dissolution of hemihydrate involves detachment of molecules from a solid surface in contact with water

$$
\mathrm{CaSO}_{4} \cdot 0.5 \mathrm{H}_{2} \mathrm{O}_{(\mathrm{s})} \stackrel{\mathrm{H}_{2} \mathrm{O}}{\longrightarrow} \mathrm{CaSO}_{4} \cdot 0.5 \mathrm{H}_{2} \mathrm{O}_{(\mathrm{aq})}
$$

2. Diffusion involves the transport of solution components through the paste pores and nucleation which initiates the precipitation of solids (dihydrate is less soluble in water).

3. A complex reaction between simple ions to form ion complexes together with hydration of a hemihydrate into dihydrate.

$$
\mathrm{CaSO}_{4} \cdot 0.5 \mathrm{H}_{2} \mathrm{O}(\mathrm{aq})+1.5 \mathrm{H}_{2} \mathrm{O} \stackrel{\mathrm{H}_{2} \mathrm{O}}{\longrightarrow} \mathrm{CaSO}_{4} \cdot 2 \mathrm{H}_{2} \mathrm{O}(\mathrm{s})
$$

4. Adsorption and accumulation of ions or other molecular units at an interface (crystallization). 
These processes may operate in series, parallel or in some complex combinations. Each stage can be a rate-controlling stage.

The stages are affected by the presence of admixtures leading to a possible control of the hydration process and material properties. Garg et al. [8] have studied the properties of fluorogypsum - a slag composite binder. They found much improved flexural strength, prolonged setting time and increased thermal conductivity in comparison to gypsum without additives. Tesárek et al. [11] found that gypsum porosity increased quickly with an increasing amount of water in the mixture.

One of the main polymeric substances added to construction materials as admixtures are cellulose ethers. Cellulose is one of natural polymers having crystalline complex structure. This feature makes it insoluble in water. On the other hand, the crystalline region of cellulose can be disrupted due to modification when the hydroxyl group of cellulose is substituted with methoxy, hydroxypropyl and hydroxyethyl groups. Thus formed cellulose ethers (as organic admixtures) are soluble in water also as a result of amorphous characteristics [12]. The cellulose ethers like hydroxypropylmethyl cellulose (HPMC) and hydroxyethylmethyl cellulose (HEMC) are non-toxic and edible. In the dissolved state they are viscous enough to easily form films. Thus they found widespread use in medicine and architecture.

HEMC is one of cellulose ethers affecting the properties of construction materials and improving their workability. In the case of cement it was proved that macromolecules had an impact on cement and gypsum hydration delay [13,14]. The authors predicted that the biggest effect on the hydration delay had the presence of a methoxyl group.

Plank et al. $[15,16]$ showed that HEMC improved water retention of cement and gypsum. Already a $0.3 \%$ dose of HEMC causes $97 \%$ of water retention capability. HEMC doses higher than $1 \%$ produce extremely viscous cement pastes. This effect is dependent on the molecular weight of the polymer sample. An increase in filtrate viscosity may play a role in the working mechanism of HEMC [17]. Currently, the main applications of HEMC and other cellulose ethers are wall plasters, floor screeds, water-proofing membranes, joint compounds for gypsum board paneling and cement tile adhesives.

Another polymer used also as an admixture in construction materials is poly(vinyl acetate) (PVAC) and its copolymers. It was found that the use of PVAC as a plasticizer of cement or gypsum [18] improved material adhesion to the substrate. Furthermore, the application of PVAC does not require preservatives and fungicides, the polymer inhibits the growth of mildew [19].

In this paper, both HEMC and PVAC polymers are chosen as admixtures to modify gypsum properties which have not been sufficiently tested up to now. Research methods such as calorimetry, setting and mechanical tests help us to discuss and identify the effect of polymer admixture on the kinetics of solid gypsum plaster formation leading to its specific properties.

\section{MATERIAL AND METHODS}

\subsection{Materials}

Material used in this study was gypsum - calcium sulphate hemihydrate ( $\beta$ form) supplied by Dolina Nidy (Poland). The gypsum meets the requirements of standard PN- EN 13279-1:2009. Calcium sulphate $\left(\mathrm{CaSO}_{4}\right)$ in gypsum amounted to $90.98 \%$. Other components were: $\mathrm{CaCO}_{3}-2.79 \%, \mathrm{SiO}_{2}-1.62 \%$, montmorillonite $-3.07 \%$, illite $-0.79 \%$, and chlorite $0.16 \%$. Distilled water was used for mixing gypsum with admixtures. Hydroxyethylmethyl cellulose $(\mathrm{HEMC})(\mu=3000$ $\mathrm{mPa} * \mathrm{~s}$ ) and poly(vinyl acetate) (PVAC) were supplied by Atlas Company (Poland).

\subsection{Preparation of samples}

The following samples were prepared to use in calorimetric, setting time and mechanical studies: gypsum powder (hemihydrate) without admixtures, gypsum doped with $1 \%$ HEMC or $1 \%$ PVAC. Various amounts of water from 35 to $50 \%$ by weight (water to gypsum ratio $x=0.54-1.0$ ) were added. The samples were prepared according to standard PN-86 B04360 (Plasters, Test methods, Physical characteristic determination).

Polymer admixtures in appropriate amounts were first dissolved in distilled water at room temperature. Then, the composition with gypsum powder was vigorously mixed for 30 seconds using a mechanical stirrer.

\subsection{Calorimetric studies of the samples}

A Mettler differential scanning calorimeter (DSC) model FP90 was used to study the hydration process of gypsum powder hemihydrate with admixtures. Immediately after mixing samples of the paste (about $10 \mathrm{mg}$ ) were transferred in special capsules into the calorimeter chamber for measurements. At the first step the samples were kept for 2 hours at constant temperature of $30^{\circ} \mathrm{C}$. Thus, heats of hydration and crystallization of hemihydrates-gypsum samples were investigated in 
isothermal conditions. Then, at the second step the samples were heated at constant rate of $10^{\circ} \mathrm{C} / \mathrm{min}$ from $30^{\circ} \mathrm{C}$ to $250^{\circ} \mathrm{C}$ in the air to measure dehydration by evolution of various states of water in the hydrated product.

\subsection{Setting tests}

The setting time was measured at room temperature using a Vicat's device (Master, Italy) equipped with a stainless steel needle and ebonite ring. Contact surface of the needle was polished after every measurement. The study consists in a measure of free needle penetration in to the gypsum paste every 30 seconds. The study was conducted according to standard PN-86 B04360 (Plasters. Test methods. Physical characteristic determination.).

\subsection{Mechanical tests}

Mechanical bending test of flexural Young modulus and strength was carried out using Instron 3345 (Instron, USA).

Samples were prepared for the bending test by spreading gypsum plaster into rubber molds attached to the glass plates. Dimensions of the molds were $50 \mathrm{~mm} / 18 \mathrm{~mm} / 5 \mathrm{~mm}$. The tests were repeated 6 times for every sample. Before the experiment the entire mold was smeared with oil. The applied samples were set for 48 hours at room temperature.

The test was conducted according to standard PN-86 B-04360 (Plasters. Test methods. Physical characteristic determination).

\section{RESULTS AND DISCUSSION}

Gypsum samples prepared with various water to gypsum ratios and containing two polymer admixtures - HEMC or PVAC (in weight fraction 1\%) were studied by DSC in setting and mechanical experiments. Results are shown graphically and discussed. A difference between the effect of both admixtures on the process of gypsum - calcium hemihydrate sulphate hydration/crystallization kinetics measured by DSC and setting tests is shown.

\subsection{Setting time}

Setting of material is a transition period during which the physical state of material changes from paste to solid. This transformation occurs as a result of the development of hydration products which cause rigid connections between hydrating grains. It is usually characterized by two points in the hydration process, namely initial and final setting time. The development of connected hydration product which reflects the transition of material state was measured by the penetration resistance technique (Vicat needle test).

Figures 1 and 2 show selected results of the Vicat needle tests. The beginning of the setting period was estimated as the first inflection point on $h=f(t)$ (where $h$ is the height of the needle). The time of setting was measured as the time of the intersection of straight line on $\mathrm{h}=\mathrm{f}(\mathrm{t})$ curve. The time from the onset of the experiment to the beginning of the setting period is known as the induction period $t_{i}$.

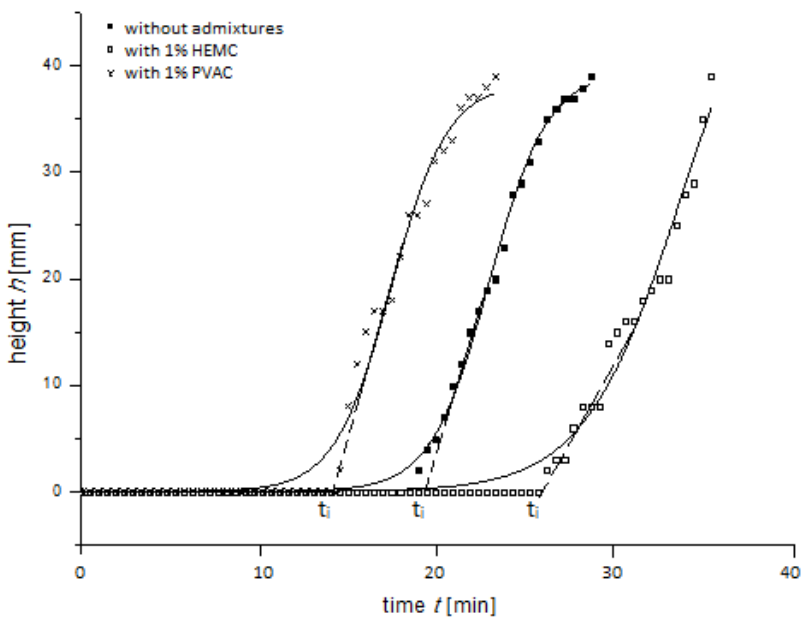

FIG. 1. SETTING PROCESS $h=f(t)$ OF SAMPLES WITH WATER TO GYPSUM RATIO $x=0.60$.

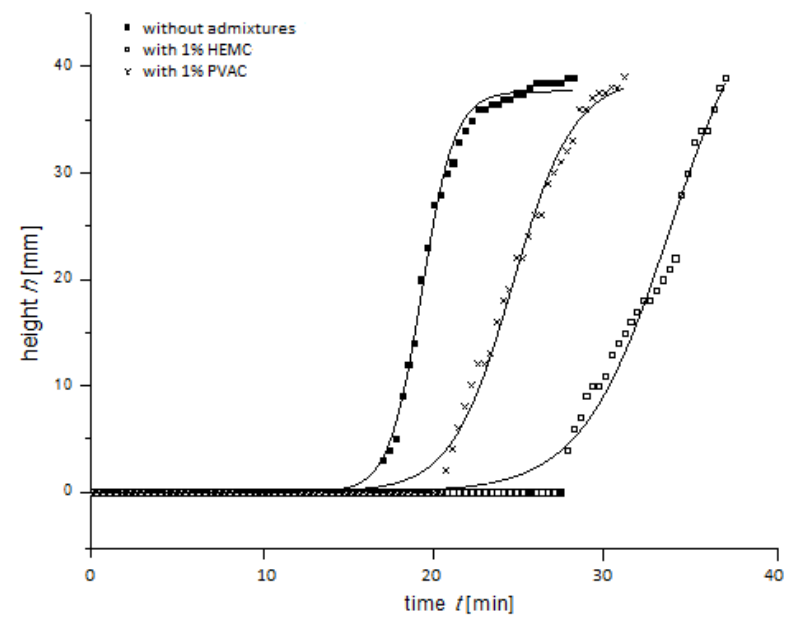

FIG. 2. SETTING PROCESS $h=f(t)$ OF SAMPLES WITH WATER TO GYPSUM RATIO $\boldsymbol{x}=\mathbf{0 . 8 2}$. 
In the case of higher water content (higher water to gypsum ratio) the initiation of setting process followed later (induction time increased). Gypsum setting time was prolonged with a rising content of water.

Figure 1 shows the setting process of samples with water to gypsum ratio x equal to 0.60 . The PVAC admixture reduces the setting induction period, while HEMC extends it. For higher water content the trend changes. Starting from $\mathrm{x}=0.67$, both HEMC and PVAC admixtures (Fig. 3) extend the setting induction time (Fig. 2 for $\mathrm{x}=0.82$ water to gypsum ratio).

The observed retardation of setting in the case of the applied polymers can be the effect of disturbed diffusion of ions (also water) and molecules to the binder surface due to relatively rigid polymer molecule conformation in the water phase. No electrostatic interactions of polymer active groups with the binding surface of gypsum are predicted because the gypsum zeta potential is close to zero [20].

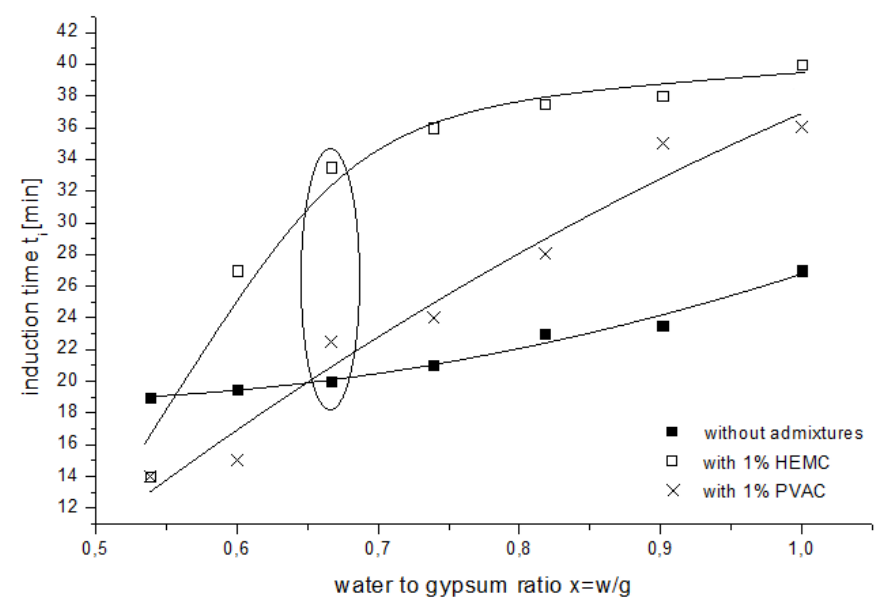

FIG. 3. DEPENDENCE OF INDUCTION PERIOD $t_{i}$ ON INITIAL WATER TO GYPSUM RATIO $x$.

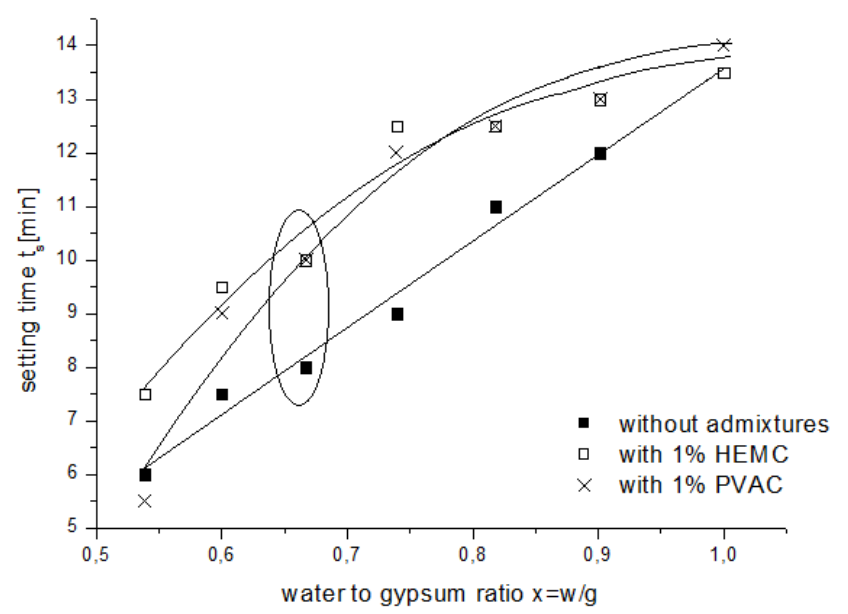

FIG. 4. DEPENDENCE OF SETTING TIME $t_{s}$ ON INITIAL WATER TO GYPSUM RATIO $x$.

Figure 3 presents the dependence of induction period on initial water to gypsum ratio $x$ for the studied samples. Acceleration of the hydration process of hemihydrates caused by the presence of admixture in the case of low water to gypsum ratio $x$ (the induction period is shorter) is observed.

In the case of higher water content $(x>0.67)$ the induction period starts to be longer due to limited diffusion process of gypsum (ions) molecules leading to nucleation and crystallization.

Figure 4 shows setting time versus $x$ ratio for the studied samples. The admixtures significantly influence the setting time interval of gypsum. They cause delay of the induction period and increase of the setting time (decreasing rate of hydration for $x>0.67)$.

\subsection{Hydration/crystallization process}

Reaction of gypsum powder - sulphate hemihydrate with water [9] is divided into three main stages and involves a set of coupled chemical processes in the gypsum - water system:

1. A nucleation period (occurring in induction time) starts after gypsum powder is mixed with water solvent. First, gypsum hemihydrate is dissolved in water. The dissolution involves detachment of molecular units from a solid surface in contact with water as well as diffusion and transport of solution components into paste volume. The solution becomes supersaturated with respect to $\mathrm{Ca}^{2+}$ and $\mathrm{SO}_{4}{ }^{2-}$ ions which leads to the precipitation of solid grains (crystalline structure) - nucleation process.

2. An acceleration period in which complex reactions between ions or molecular compounds adsorbed on solid surfaces occur - hydration/crystallization process.

3. A deceleration period in which very slow adsorption and accumulation reactions of ions or other molecular units occur at an interface. The late stage of hydration is thus controlled by a diffusion process. 
The rate of all the reactions can be changed if a third nonreactive material (polymer admixture) adheres to gypsum particles reducing their reactive surface or solution viscosity. For example, the induction period can be prolonged with [21]

a) reduced diffusion of water and calcium ions at the gypsum surface because the adsorbed polymer (if so) hinders the process,

b) formation of a complex between calcium ions and polymer,

c) change in the growth kinetics and morphology of hydrated phases caused by the dispersive action of the polymer.

Experimental observations suggest that the rate of formation of gypsum hydration product is a rate-controlling process of hydration at early stages [22]. These observations lead to the development of hydration kinetics models based on nucleation and growth phenomena.

The simplest and most widely used equation proposed by Avrami [23] and independently by Johnson and Mehl [24] and Kolmogorov [25] is derived using the assumption within the transforming (from liquid to crystal) volume. The well known results are described by the Avrami equation as follows:

$$
X(t)=1-\exp \left(-K t^{n}\right)
$$

where:

$X(t)$ - is the volume fraction of crystalline phase that has transformed at time $t$,

$K-$ is the combined rate constant that involves the rates of growth and nucleation,

$n$ - Parameter dependent on the mechanism of nucleation and dimensionality of growth.

If $n \approx 1$, the growth is one-dimensional (needle). When $n \approx 2$ two dimensions are observed and at $n \approx 3$ isotropic growth (sphere) appears. The authors [26] first applied the Avrami equation to $\mathrm{C}_{3} \mathrm{~S}$ hydration data and they reported an exponent value of $n=$ 3. However, X-ray diffraction data resulted in a low value of $n=1$. Similar values of $n$ close to unity were reported more recently [27] from kinetic data obtained from the measurement of pore structure development. However, Thomas [28,29] showed that when the Avrami equation is applied to calorimetry rate data (limited to the rate peak), the value of $n$ was 3.7 (the value close to 4 denoted a phase boundary control, three-dimensional growth and thermal nucleation).

The volume of the transformed phase will increase with the simple power law (Avrami equation) in the early stages of the process before adjacent regions of growing product are impinged. Thus overall growth rate in the system decreases with time.

It is commonly assumed that hydration is diffusion controlled by the rate at which the reactants can diffuse through the nanoporous layer of hydration product around the remaining unhydrated gypsum particles. The point in which the hydration process shifts away from nucleation and growth is not well established, but it is an important aspect of the hydration process.

The increasing use of mineral or polymer admixtures to gypsum materials leads to the question how the admixtures can affect hydration rate especially at early stages.

A wide range of properties, including heat of hydration phase, volume fraction, chemical shrinkage, percolation of capillary porosity and setting time, can be followed as hydration (and crystallization) proceeds.

Hydration/crystallization process of gypsum pure and with admixtures was studied using DSC. It is a direct way to monitor the extent of reactions by measuring the heat flow rate. Figure 5 shows DSC thermograms of 1 . pure gypsum, 2. gypsum with $1 \%$ HEMC by weight, 3. gypsum with $1 \%$ PVAC by weight, at $w / g$ ratio equal to 0.54 . Gypsum hydration occurs in the main three-stage processes: nucleation, acceleration and deceleration. The crystallization process occurs faster in the case of sample 1 (without admixtures). The HEMC and PVAC admixtures cause a delay of the hydration/crystallization process due to a decrease of nucleation rates of the reaction products (lower value of $\log K$, Table 1 ). 


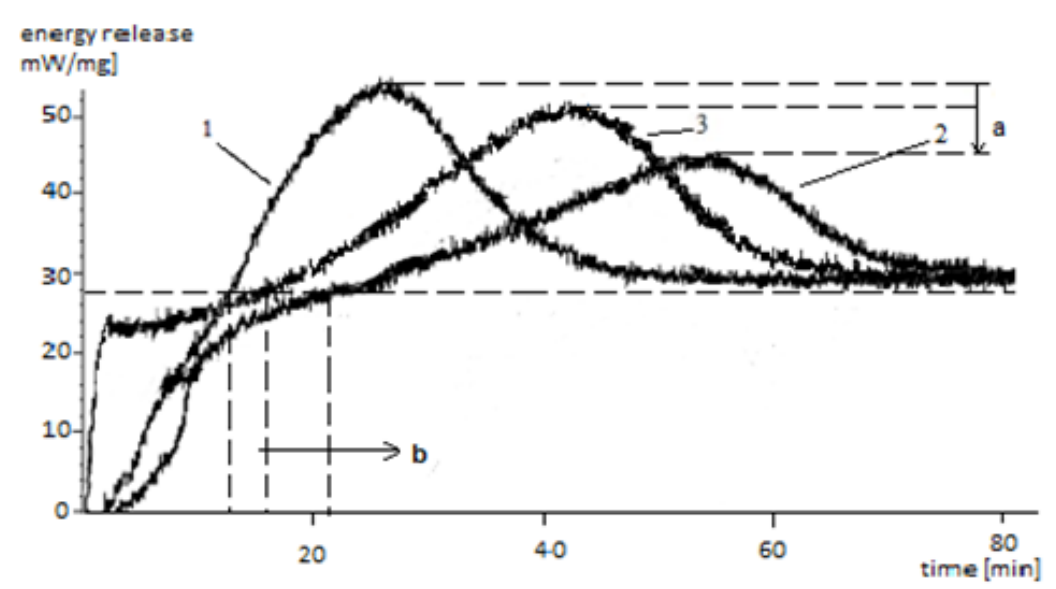

FIG. 5. DSC THERMOGRAMS AT ISOTHERMAL CONDITIONS, $T=30^{\circ} \mathrm{C}$ FOR GYPSUM SAMPLES WITH $X=0.54 .1$ - WITHOUT ADMIXTURES, 2 - WITH 1\% HEMC, 3 - WITH 1\% PVAC; A - INFLUENCE OF THE ADMIXTURE ON THE MAXIMUM HEAT RELEASE RATE; B - INFLUENCE OF THE ADMIXTURE ON THE ONSET OF HEAT RELEASE.

TABLE 1

$\log$ K AND n PARAMETERS OBTAINED USING THE AVRAMI EQUATION (DATA OBTAINED BY DSC ANALYSIS AND SETTING TESTS - ACCELERATION PROCESS).

\begin{tabular}{|c|c|c|c|c|}
\hline \multirow{2}{*}{ Sample } & \multicolumn{2}{|c|}{ DSC $\boldsymbol{x}=\mathbf{0 . 5 4}$} & $\boldsymbol{2}$ & $\boldsymbol{n}$ \\
\cline { 2 - 5 } & $\log \boldsymbol{N}$ & 1.4 & -3.4 & 1.3 \\
\hline 1. & -1.8 & 1.4 & -3.5 & 1.3 \\
\hline 2. & -2.6 & 1.2 & -3.6 & 1.4 \\
\hline 3. & -2.3 & &
\end{tabular}

In the case of calorimetric studies a volume fraction of increasing transforming phase $X$ is taken (in Avrami plot) as a ratio of crystallization/hydration heats:

$$
X=\Delta H_{x} / \Delta H_{c}
$$

where

$\Delta H_{x}$ - part of heat released changing with time,

$\Delta H_{c}$ - total heat release.

The heat transformation data are fitted reasonably well to the Avrami equation.

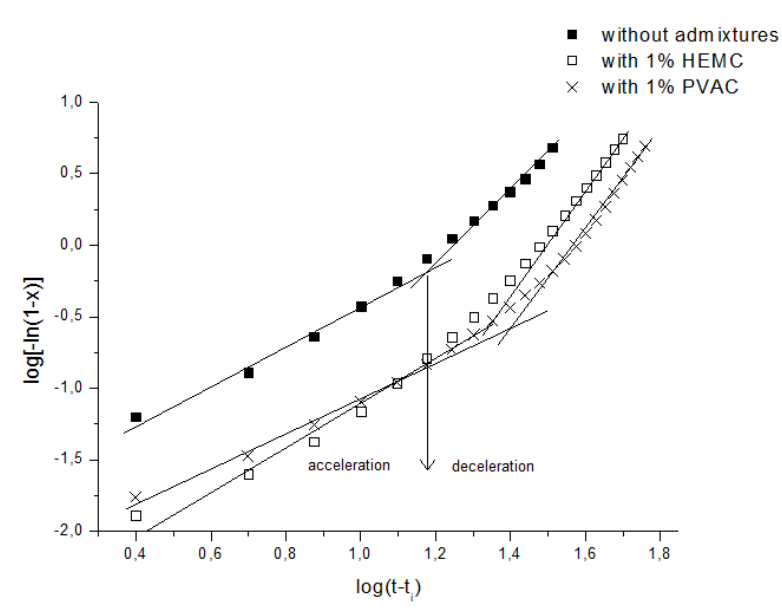

FIG. 6. $\log [-\ln (1-X)]$ versus $\log \left(t-t_{i}\right)$ for $x=0.54$.

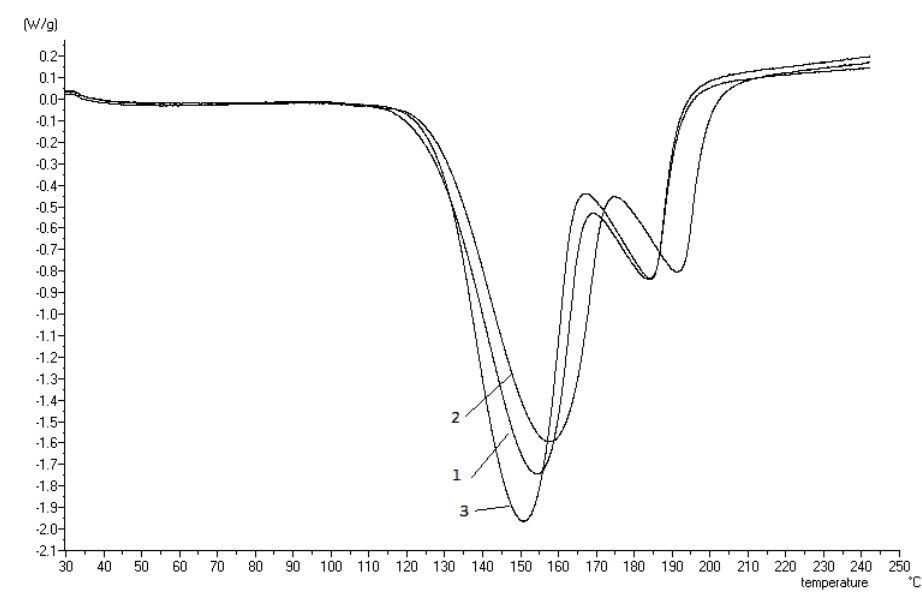

FIG. 7. DSC THERMOGRAMS OF GYPSUM SAMPLES: pure (1) and with $1 \%$ admixtures of HEMC (2), PVAC (3) when $x=0.54\left(\beta=10^{\circ} \mathrm{C} / \mathrm{min}\right)$. 
Figure 6 presents an example of Avrami plots in the double log form. It shows two regions of fitting, which can be caused by a complex chemical reaction of gypsum with water. The calculated parameters $\log K$ and $n$ of the equation are given in Table 1. The results indicate that the additives behave as efficient disturbing agents in the nucleation and crystallization process of gypsum - lower $\log K$ value.

In respect to the presented study on setting time, the volume fraction of crystalline phase $X$ in the Avrami plot is taken as the ratio:

$$
X=h / h_{\max }
$$

where $h$ and $h_{\max }$ are the height of needle changing with time of setting and maximum height at the end of the process, respectively (Figures 3 and 4).

Parameter $n$ equal to $1.2-1.4$ means that the crystallization process during hydration proceeds in nearly one direction. Parameter $n$, measured by two different methods (calorimetry and setting tests), shows similar values. The values of $l o g$ are found to be smaller in the case of setting time experiments.

\subsection{DSC analysis of set gypsum}

After two hours of crystallization (hydration) at $30^{\circ} \mathrm{C}$, the samples were heated from 30 to $250^{\circ} \mathrm{C}$ at heating rate $\beta=10^{\circ} \mathrm{C} / \mathrm{min}$ in the DSC apparatus. Results in the form of thermograms are shown in Fig. 7.

The peaks in Fig. 7 denote the heat of bound water evaporation. The values of heat are shown in Table 2 together with corresponding peak temperatures T. The observed temperature range from $130^{\circ} \mathrm{C}$ to $200^{\circ} \mathrm{C}$ is associated with dehydration of gypsum by transition from dihydrate into hemihydrate.

TABLE 2

THE VALUES OF $\mathrm{dH}_{1}, \mathrm{dH}_{2}, \mathrm{~T}_{1}, \mathrm{~T}_{2}$ OBTAINED FROM DSC $(\mathrm{x}=0.54)$.

\begin{tabular}{|c|c|c|c|c|c|}
\hline $\mathrm{Sr}$ & Sample & $d \boldsymbol{H}_{1}[\mathrm{~J} / \mathrm{g}]$ & $\boldsymbol{T}_{1}\left[{ }^{\circ} \mathrm{C}\right]$ & $\boldsymbol{d H}_{2}[\mathrm{~J} / \mathrm{g}]$ & $\boldsymbol{T}_{2}\left[{ }^{\circ} \mathrm{C}\right]$ \\
\hline 1 & $\mathrm{H}_{2} \mathrm{O}$ with gypsum & 187.0 & 153.9 & 38.5 & 185.7 \\
\hline 2 & $\mathrm{H}_{2} \mathrm{O}$ with gypsum and 1\% HEMC & 196.0 & 158.0 & 44.5 & 193.6 \\
\hline 3 & $\mathrm{H}_{2} \mathrm{O}$ with gypsum and 1\% PVAC & 219.0 & 150.6 & 46.7 & 186.9 \\
\hline
\end{tabular}

$T_{1}$ - peak temperature of dehydration in the first step $\left[{ }^{\circ} \mathrm{C}\right]$ - bound water;

$\mathrm{T}_{2}$ - peak temperature of dehydration in the second step - bound water $\left[{ }^{\circ} \mathrm{C}\right]$;

$\mathrm{dH}_{1}$ - heat of dehydration in the first step [J/g] - for $1 \mathrm{~g}$ of sample;

$\mathrm{dH}_{2}$ - heat of dehydration in the second step $[\mathrm{J} / \mathrm{g}]$ - for $1 \mathrm{~g}$ of sample.

The bound water is divided into the adsorbed bound water (hygroscopic) where the layer of cations is strongly associated with solid particles to form hydrated crystals and weaker bounded water (by hydrogen bonds) called diffused water. The release temperatures are $150.6<\mathrm{T}_{1}<158.0$ and $185.7<\mathrm{T}_{2}<193.6$, respectively (see Table 2 ).

No free water peak $\left(\approx 100^{\circ} \mathrm{C}\right)$ is observed for low $x$ (in the case of drying at room temperature for $24 \mathrm{~h}$ ).

The heat of dehydration $d H_{1}, d H_{2}$ and temperatures $T_{1}, T_{2}$ can indicate the effects associated with the presence of the polymeric additive system. It was found (calculated) that the amount of water released from both aqueous states, i.e. hygroscopic and diffused, associated with the gypsum structure is proportional to the gypsum mass in the material, which increases with decreasing X (gypsum to water ratio), even in the case when a polymer is added. The average calculated values of heat absorbed during the dehydration - transformation of gypsum dihydrate to hemihydrate - associated with each of the states for pure gypsum, gypsum plaster with PVAC and gypsum plaster with HEMC are: $d H_{l}=290.0,271.0$ and 269 $\mathrm{kJ} / \mathrm{g}$; and $\mathrm{dH}_{2}=66.7,63.8$ and $56.2 \mathrm{~kJ} / \mathrm{g}$, respectively (for $1 \mathrm{~g}$ of gypsum). The amount of heat consumed during dehydration of the adsorption state is about $17-19 \%$ of the total heat of bound water and it does not depend on the presence of the polymeric additives.

\subsection{Results of mechanical tests}

The results of mechanical tests are shown in Figures 8 and 9. The graphs present the dependence of flexural strength $\sigma_{\max }$ and E modulus on water to gypsum ratio $\mathrm{x}$. 


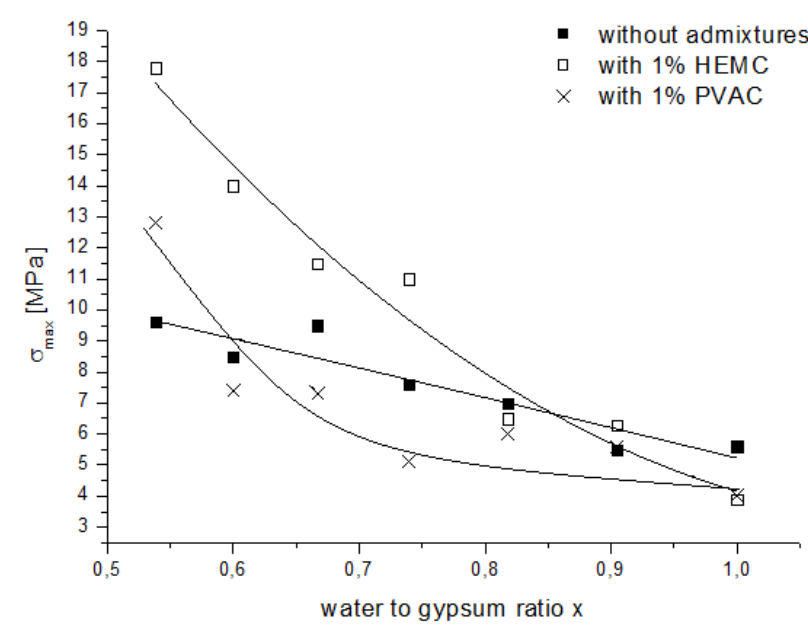

FIG. 8. Bending flexural strength $\sigma_{\max }$ versus $x$ (initial water to gypsum ratio). Bar error $\Delta \sigma_{\max } E 1$ MPa

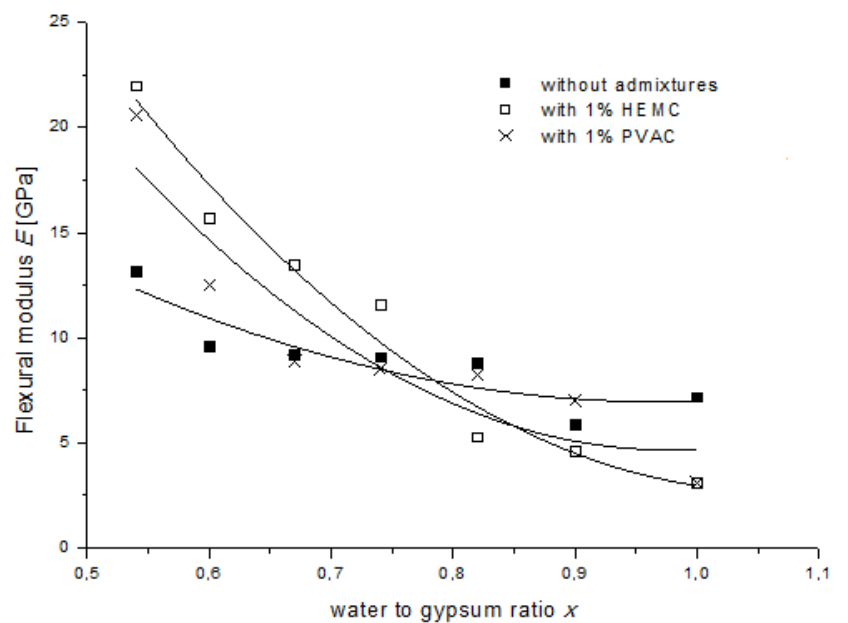

FIG. 9. Dependence of flexural modulus $E$ on $x$ (initial water to gypsum ratio). Bar error $\Delta \mathrm{E}$ E2 GPa

It can be seen that both flexural strength properties decrease with increasing water amount. This trend is observed for all samples being studied.

It can be seen that the influence of admixtures, such as HEMC or PVAC, on mechanical properties of gypsum is important merely for gypsum samples with low water content. Higher water content causes increased induction and setting times, while residual water acts as a plasticizer making larger pores in gypsum plaster.

The amount of bound water is almost the same in all tested samples (the differences are small), so that the amount of free water must be similar for the three discussed samples of the same $\mathrm{x}$. Thus, porosity associated with the evaporation (free water release) should be the same. It is predicted that the polymers are deposited in the form of a film layer in the pore structure improving mechanical properties of gypsum. In the case of high $\mathrm{x}$ the decreasing values of modulus and flexural strengths are observed. Thus, there is a pronounced effect of the polymer on the mechanical properties for low $x$ values. Assuming that with an increasing $\mathrm{x}$ value the sample porosity rises and taking into account the dependence of $\sigma$ and $E$ on porosity $p$ proposed by [30], we have:

$$
\begin{aligned}
& \sigma=\sigma_{0} e^{-b p} \\
& E=E_{0} e^{-b p}
\end{aligned}
$$

The values of $\sigma_{0}$ and $E_{0}$ are taken (equation 4 and 5) by approximation for $x=0.2$ - no porosity (at about 20\% water is bounded), parameter $\mathrm{b}$ is characteristic for the material. The values of $\sigma_{0}$ and $E_{0}$ are much higher for gypsum plaster with the admixture applied.

The $b$ parameter shows a difference in material properties - gypsum pores dependent on the polymer admixture.

The values of parameter $b$ for 1: sample without admixtures, 2: sample with 1\% HEMC, 3: sample with 1\% PVAC obtained from flexural strength plots are equal to: 1.6, 2.7 and 2.2, respectively. Similar values were calculated from the plots of Young modulus.

\section{CONCLUSIONS}

In this paper, the influence of selected polymers on gypsum properties, was studied by DSC, setting process and mechanical tests. The results indicate clear influence of such admixtures as HEMC or PVAC on gypsum properties, i.e. time and rate of setting, mechanical results (flexural strength and modulus), and crystallization kinetics. The setting and crystallization processes can be prolonged with reduced diffusion of water and calcium ions at the formed gypsum crystalline surface because polymer molecules in water solution hinder the process. It is predicted that the polymer film inside material pores is formed changing mechanical properties of the resulting gypsum material. Future work will be focused on the properties changing with the amount of admixtures (0.25-1.5\%) and on morphological aspects of the prepared gypsum plasters. 
The role of calcium sulphate anhydrate in hydration process is not discussed here.

\section{ACKNOWLEDGEMENTS}

The research was funded by the National Science Centre (OPUS 6) under project no. UMO-2013/11/B /ST8/04308.

\section{REFERENCES}

[1] Crépy L., Petit J.Y., Wirquin E, Martin P, Joly N. Cement and Concrete Compounds 2014;45:29-38.

[2] Etsuo S. Cement and Concrete Research 2006;36:2049-2053.

[3] Martinelli E. Cement and Concrete Research 2013;40:48-58.

[4] Jansen D., Neubauer J. Cement and Concrete Research 2012;42:327-332.

[5] Peng J. Cement and Concrete Research 2005;35:527-553.

[6] Poinot T., Bartholin M.C., Govin A., Grosseau P. Cement and Concrete Research 2015;70:50-59.

[7] Yilmaz V.T., Glasser F.P. Advances in Chemistry Research 1989;7:111.

[8] Garg M., Pundir A. Cement and Concrete Research 2014;45:227-233.

[9] Bullard J.W. et al. Cement and Concrete Research 2011;41:1208-1223.

[10] Singh N.B. Progress in Crystals Growth and Characterization of Materials 2007;53:57-77.

[11] Tesárek P., Drchalová J., Kolísko J., Rovnaníková P., Černŷ R. Construction and Building Materials 2007;21:1500-1509.

[12] Pourchez J. Cement and Concrete Research 2010;40:242-252.

[13] Pourchez J. Cement and Concrete Research 2006;36:1777-1780.

[14] Pourchez J. et al. Cement and Concrete Research 2006;36:288-294.

[15] Plank J., Kainz J., Bülichen D. Cement and Concrete Research 2012;42:953-959.

[16] Bülichen D., Plank J. Cement and Concrete Research 2013;46:66-72.

[17] Brumaud C. et al. Cement and Concrete Research 2013;53:176-184.

[18] Bojadjieva C., Glavchev I. Cement and Concrete Research 2004;34:611-613.

[19] Toxqui-López S., Olivares-Pérez A., Fuentes-Tapia I. Optical Materials 2006;28:342-349.

[20] Plank J., Hirsch Ch. Cement and Concrete Research 2007;37:537-542.

[21] Kiesewetter et al. Cement and Concrete Composites 2014;53:25-34.

[22] Thomas J.J., Biernacki J.J., Bullard J.W., Bishnoi S., Dolado J.S., Scherer G.W., Luttage A. Cement and Concrete Research 2011;41:1257-1258.

[23] Avrami M. Journal of Chemical Physics 1939;7:1103-1112 and 1940;7:1212-1124.

[24] Johnson W.A., Mehl R.F. Transactions of the American Institute of Mining and Metallurgical Engineers 1939;135:416.

[25] Kolmogorov A.N. Bulletin of the Russian Academy of Sciences: Physics 1937;255.

[26] Ridi F., Dei L., Fratini E., Chen S.-H., Baglioni P. Journal of Physical Chemistry 2003; 107:1056-1061.

[27] Jansen D., Goetz-Neunhoeffer F. Cement and Concrete Research 2013;35:71-77.

[28] Damasceni A., Dei L., Fratini E., Ridi F., Chen S.H., Baglioni P. Journal of Physical Chemistry 2002;106:11572-11578.

[29] Thomas J.J. Journal of the American Ceramic Society 2007;90:3282-3288.

[30] Colak A. Material Letters 2006;60:1977-1982. 